\title{
Optimization of proton conductors for application in solid oxide fuel cell technology
}

\author{
Konrad Świerczek ${ }^{1, *}$, Wojciech Skubida \\ ${ }^{1}$ AGH University of Science and Technology, Faculty of Energy and Fuels, Department of Hydrogen \\ Energy, al. Mickiewicza 30, 30-059 Krakow, Poland
}

\begin{abstract}
Application of proton-conducting ceramic membranes in various electrochemical devices (e.g. SOFCs, SOECs) is considered as highly beneficial. Because of a unique transport mechanism associated with proton movement in oxide materials, designing and optimization, as well as practical application of such proton conductors is a challenge. In this work, apart from discussion of literature data, authors' own results are provided, which are focused on material-related issues, including development of electrolyte and electrode materials exhibiting high proton conductivity.
\end{abstract}

\section{Introduction}

Among contemporary issues of energy sector, emission of carbon dioxide and low efficiency of conventional electricity generation systems are of crucial importance. Solid Oxide Fuel Cells (SOFC), which are electrochemical devices that convert chemical energy of a fuel (typically hydrogen) and an oxidizer directly into electricity and heat, and may exhibit high efficiency, are of special interest in an emerging hydrogen economy, i.e. usage of $\mathrm{H}_{2}$ as the energy carrier, but also in so called clean coal technologies, in which traditional, carboncontaining fuel are utilized more effectively and in more environmental friendly way [1,2]. Interestingly, if SOFC is supplied with electrical energy, it can also be used as Solid Oxide Electrolyzer Cell (SOEC), in which water can be split to produce hydrogen and oxygen. SOFC and SOEC technology relies on purely ion-conducting electrolytes (membranes), which are typically ceramic oxides conducting oxygen anions, e.g. yttria-stabilized zirconia (YSZ). Recently, in order to improve parameters of SOFCs and lower their operating temperature, a replacement of the oxygen ion-conducting electrolyte with material exhibiting proton conductivity was proposed and shown to be effective [3]. The same beneficial impact can be expected if proton-conducting membrane is used in the high-temperature electrolyzer.

In this work selected issues concerning application of proton-conducting oxides, having perovskite structure, are discussed. It seems that apart from controlled B-site substitution (acceptor-type), a simultaneous doping at the A-site can be also done, affecting considerably physicochemical properties of the materials. Consequently, structural parameters, protonic conductivity, as well as unwanted reactivity of the compounds in $\mathrm{CO}_{2}$-containing atmospheres may be adjusted. Additionally, possible new trend in development of SOFCs with proton-conducting membrane, symmetrical cell concept, is presented.

* Corresponding author: xi@agh.edu.pl 


\section{Application of SOFC and SOEC technology}

In a standard design, a single fuel cell comprises dense, gas-tight and purely ionicallyconducting electrolyte, porous electrodes (anode and cathode), as well as interconnects serving as electrical connectors. Typically, high-temperature Solid Oxide Fuel Cell is supplied by hydrogen or another gaseous fuel, such as syngas or methane, on the anode side, while an oxidant (e.g. air, pure oxygen) is supplied on the cathode side. This is due to the nature of ionic conduction in the electrolyte (conduction of oxygen ions via oxygen vacancy mechanism) and mechanism of electrochemical reactions taking place on both electrodes [4]: at the anode: $\mathrm{H}_{2}+\mathrm{O}^{2-} \rightarrow \mathrm{H}_{2} \mathrm{O}+2 \mathrm{e}^{-} ; \mathrm{CO}+\mathrm{O}^{2-} \rightarrow \mathrm{CO}_{2}+2 \mathrm{e}^{-}$or $\mathrm{CH}_{4}+4 \mathrm{O}^{2-} \rightarrow 2 \mathrm{H}_{2} \mathrm{O}+\mathrm{CO}_{2}$ $+8 \mathrm{e}^{-}$(with internal reforming); at the cathode: $1 / 2 \mathrm{O}_{2}+2 \mathrm{e}^{-} \rightarrow \mathrm{O}^{2-}$; giving overall: $\mathrm{H}_{2}+1 / 2 \mathrm{O}_{2}$ $\rightarrow \mathrm{H}_{2} \mathrm{O} ; \mathrm{CO}+1 / 2 \mathrm{O}_{2} \rightarrow \mathrm{CO}_{2}$ or $\mathrm{CH}_{4}+2 \mathrm{O}_{2} \rightarrow 2 \mathrm{H}_{2} \mathrm{O}+\mathrm{CO}_{2}$, respectively. However, relatively low power density obtained per square centimeter of the cell (on the order of single watts), as well as voltage of a single cell being in a range up to $1 \mathrm{~V}$, force to combine cells into packets and stacks, in order to construct a generator capable for delivering desired electrical power, as well as heat (up to hundreds of $\mathrm{kW}_{\mathrm{e}}$ ) $[5,6]$. Such possibility of assembling largescale systems creates vast potential concerning application of SOFCs in many areas, from household to industrial systems. In practical application, residential Combined Heat and Power (CHP) units operating on natural gas can provide additional electrical power for home usage, as well as heat for central heating and domestic hot water (Fig. 1a). However, nowadays the biggest disadvantage of such devices is their limited power output (approximately up to $2 \mathrm{~kW}_{\mathrm{e}}$ and $1 \mathrm{~kW}$ of thermal power). Consequently, so far they are rather considered as auxiliary units, not the main power source. Industrial-scale SOFC systems having higher power range are suitable for utilization of the waste heat energy, for example as shown in Fig. 1b, where gas turbine is also used for electricity generation. This kind of solution allows to improve overall efficiency up to ca. $60 \%$ [7].

Despite of many material-related problems (corrosion, thermal degradation, etc.), high operating temperature of SOFCs, up to $1000^{\circ} \mathrm{C}$, has some advantages. The most important one is the mentioned above (last overall reaction) possibility of usage of carbohydrates as a fuel, without a need for a complicated and expensive external reforming. Inside the cell fuel, methane can be catalytically converted to hydrogen and carbon oxide, forming synthesis gas, which then can be electrochemically oxidized on the anode to carbon dioxide and steam, generating electricity and heat. The main reason limiting usage of methane as a fuel is its contamination with sulfur compounds, which cause cell poisoning, and results in a lowering of efficiency of the system. Higher concentrations of sulfur compounds can even cause mechanical destruction of the cells [8].

Another reason hindering usage of $\mathrm{CH}_{4}$ is carbon deposition, which can occur on the anode as a result of uncontrolled fuel reforming. This can result not only in an efficiency decrease, but also in mechanical destruction of the unit. There are several ways to prevent such the effect, for example, steam excess or some oxygen can be applied, but it is always connected with lowering of the efficiency, as well as a decrease of lifetime of the device [10, 11]. Search for alternative materials that will be resistant to the abovementioned sulfur and carbon deposition-related problems is currently ongoing in many laboratories. In the case of SOECs, apart from production of hydrogen and oxygen from a splitting of water, an interesting other application can be also considered. If SOEC unit with the oxygenconducting electrolyte is supplied with $\mathrm{H}_{2} \mathrm{O}, \mathrm{CO}_{2}$, as well as with electrical energy, $\mathrm{H}_{2}$ and $\mathrm{CO}$ (as well as $\mathrm{O}_{2}$ ) can be produced, which can be used for production of synthetic fuels [12]. 
a)

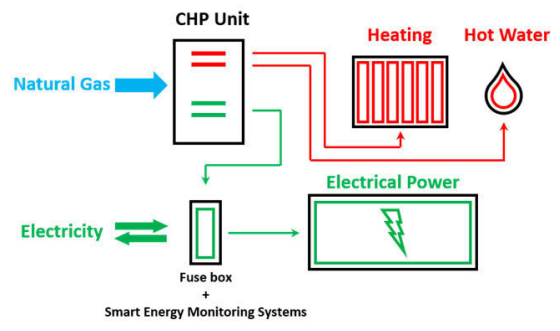

b)

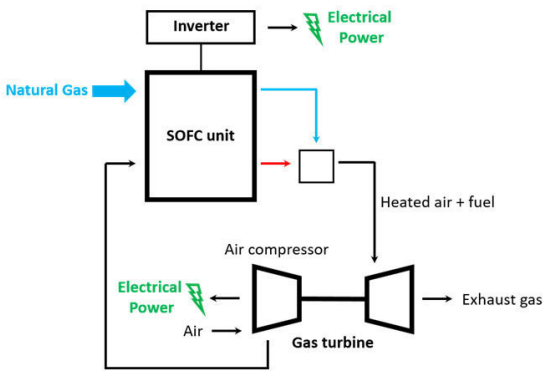

Fig. 1. a) CHP generator for domestic use, scheme [9]; b) SOFC system with gas turbine [7].

Replacement of conventional electrolyte transporting oxygen anions by protonconducting compounds in various electrochemical devices is a relatively new idea. Such cells are often abbreviated as PCFCs, Proton Ceramic Fuel Cells, and are described in more details in the following chapter.

\section{Proton Ceramic Fuel Cells and Electrolyzer Cells}

Usage of proton conductor as electrolyte brings important advantages, concerning operation of SOFCs and SOECs. Apart from a change of direction of flow of ions in the electrolyte, the most important ones are related to changes of the reactions taking place at the respective electrodes. If supplied with hydrogen and oxygen, water, being a product of the reaction in the fuel cell, is formed on the cathode side of the cell (Fig. 2a), rather than at the anode. This enables a more efficient use of the fuel supply downstream [13]. The same effect concerns water vapor electrolyzer, which produces hydrogen from water vapor (Fig. 2b). If proton-conducting electrolyte is used, the efficiency of the process increases, and the obtained product (i.e. hydrogen) is undiluted. Other advantages are related to a fact that the Nernst voltage is maintained at a high level, and there are no problems with reduced stability of the anode, resulting from a presence of the water vapor [4]. Proton-conducting electrolytes show also higher values of the conductivity in the intermediate temperature range (400-600 ${ }^{\circ} \mathrm{C}$ ), which is especially interesting concerning application [13]. Unfortunately, it is not possible to fuel PCFC stack directly with hydrocarbon fuels.

a)

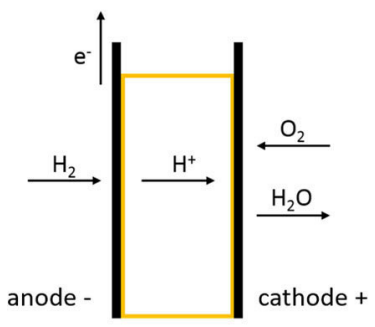

b)

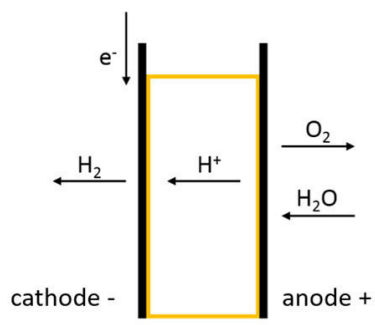

Fig. 2. Diagram of a fuel cell (a), and water vapor electrolyzer (b), with proton-conducting electrolyte.

The basis for design of Protonic Ceramic Fuel Cells and also Solid Oxide Electrolyzer Cells with proton-conducting electrolyte are materials from a group of so called High Temperature Proton Conductors (HTPC) [14]. This group of oxides consists mostly of acceptor-type substituted perovskite-type oxides, and is discussed below.

While all the above indicates that proton conductors are promising electrolytes for the intermediate or low temperature PCFCs and SOECs, the reported so far performance is still inadequate for practical application, primarily due to a lack of proper electrode materials, which would be compatible with such electrolytes, as well as fundamental issues concerning 
presence of mixed, proton, oxygen ion and electron conduction in a particular material at the same time [15]. In most cases, when it comes to testing of the proton- conducting electrolytes in the cells, mixture of electrolyte material and metal oxide (which during operation is reduced to metal) is used as the anode. Typically $\mathrm{NiO}$ is utilized, and its cermets with the electrolyte powder display excellent catalytic properties for hydrogen oxidation, as well as allow for a good current collection. Unfortunately, there is no "ideal anode material" known, i.e. exhibiting mixed protonic and electronic conductivity at the same time, which would allow to use a single phase-type anode material (Fig. 3a). With usage of cermets, the electrochemical reaction at the anode is limited to the triple phase boundary (electrolyte, anode material and gas phase), marked as a circle in Fig. 3b. Unfortunately, nickel metal in the cermets tends to agglomerate after prolonged operation, leading to a reduced three-phase boundary and increased cell's resistance [4]. That indicates the importance of searching for new materials, also oxides, which can replace Ni.

a)

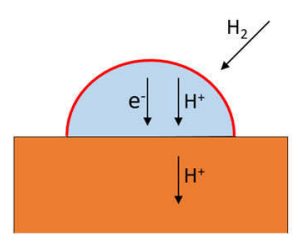

b)

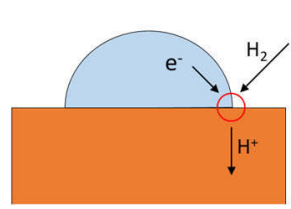

c)

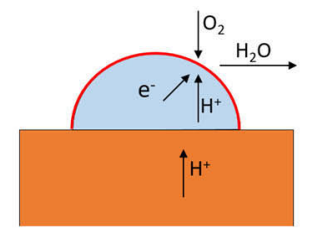

d)

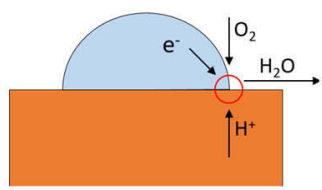

Fig. 3. Anode and cathode reactions in PCFC: a, c) mixed protonic-electronic "ideal" electrode, b, d) only electronically-conducting electrode (in this case usage of cermet-type electrode is necessary).

The electrochemical reaction at the cathode in PCFCs is shown in Fig. 3c and d. Due to similar issues, no "ideal" cathode material is available, and also cermets are utilized, in which, apart for the electrolyte phase, secondary material having good electrical conductivity is needed. Typically, such materials are $\mathrm{ABO}_{3-\delta}$-type perovskites, which show high catalytic activity towards oxygen reduction, e.g. $\mathrm{La}_{1-\mathrm{x}} \mathrm{Sr}_{\mathrm{x}} \mathrm{Co}_{1-\mathrm{y}} \mathrm{Fe}_{\mathrm{y}} \mathrm{O}_{3-\delta}$. Interestingly, such materials are actually used in SOFCs with the oxygen-conducting electrolyte [15, 16]. As can be concluded, in the case of cells with proton-conducting electrolyte, composite-type electrodes must be used, in which the overall efficiency is related the triple phase boundary length and density in the electrode volume. Therefore, optimization of the composites (from the point of view of selection of materials and also microstructure) is necessary in order to obtain functional electrodes. Illustration of PCFC with a mixed ionic-electronic conducting composite-type electrodes is shown in Fig. 4.

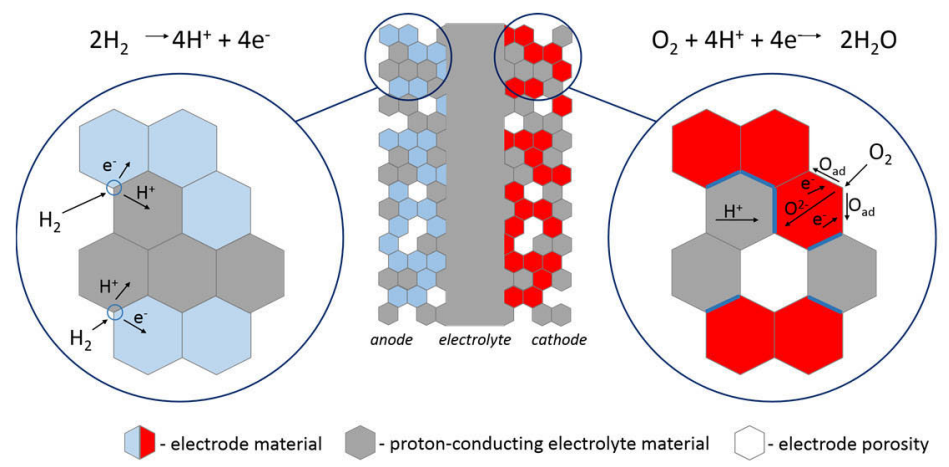

Fig. 4. Schematic illustration of PCFC with mixed ionic-electronic conducting composite electrodes. Zoomed areas represent model of expected charge transport mechanisms in the anode and cathode. Blue regions marked on the sides correspond to the areas where electrode reactions are expected to occur. 


\section{Proton transport in perovskite-type oxides}

The mentioned HTPC oxides do not have protons in their structure, and for the proton conduction occurrence, humidified atmosphere is needed. Typically, these compounds possess perovskite-type crystal structure, however other material are also known, as briefly summarized in the chapter 5. In the dry atmosphere such perovskite-type oxides are characterized by a rather insulating properties, with a very low value of the $p$-type electronic conductivity. In the presence of water vapor and at high temperatures, protons ca be built into crystal structure of the material. In most cases it is easily achieved due to high negative enthalpy of the process [4]. Proton incorporation causes lowering of electronic component of the conductivity and an appearance of the high protonic conductivity with low activation energy, which occurs at a relatively wide range of temperatures and oxygen partial pressures $[17,18]$. Protons are absorbed into the structure of HTPC from the surrounding atmosphere that contains water vapor and/or hydrogen, according to the following chemical reactions $\mathrm{H}_{2} \mathrm{O}+\mathrm{V}_{\mathrm{O}}^{\bullet \bullet}+\mathrm{O}_{\mathrm{O}}^{\mathrm{x}} \leftrightarrow 2 \mathrm{OH}_{\mathrm{O}}^{\bullet}$ and $\mathrm{H}_{2}+2 \mathrm{O}_{\mathrm{O}}^{\mathrm{x}} \leftrightarrow 2 \mathrm{OH}_{\mathrm{O}}^{\bullet}+2 \mathrm{e}^{\prime}$, respectively.

In the case of perovskite oxides, the second reaction is considered to be dominant. The water vapor dissociates at the surface of the material, forming hydroxide ion and the proton, then, the $\mathrm{OH}^{-}$ion takes place of the oxygen vacancy site, while proton forms a bond within the oxygen lattice [19]. The adsorption of water is an exothermic reaction, which explains the dominant nature of the proton conductivity at low temperatures, while usually hightemperature conductivity is dominated by the vacancy mechanism (conduction of oxygen) [20]. The above-described mechanism of the appearance of mobile protons in the structure of the oxide requires presence of the oxygen vacancies. This can be realized by an appropriate introduction of the acceptor-type dopant. To form oxygen vacancies in perovskite oxides, in which the $A$ cation is at the +2 oxidation state and the $B$ cation possesses +4 charge, a partial substitution by the trivalent cation (M) at the $\mathrm{B}$ site is used. The reaction of formation of the oxygen vacancies in dry atmosphere can be written as [19]: $2 \mathrm{~B}_{\mathrm{B}}^{\mathrm{x}}+\mathrm{O}_{\mathrm{O}}^{\mathrm{x}}+\mathrm{M}_{2} \mathrm{O}_{3} \leftrightarrow 2 \mathrm{M}_{\mathrm{B}}^{\prime}+$ $\mathrm{V}_{\mathrm{O}}^{\bullet}+2 \mathrm{BO}_{2}$. In the steam-containing atmosphere protons can be incorporated directly as charge compensating defects during synthesis, which takes place according to the equation [4]: $\mathrm{M}_{2} \mathrm{O}_{3}+2 \mathrm{AO}+\mathrm{H}_{2} \mathrm{O}_{(\mathrm{g})} \leftrightarrow 2 \mathrm{~A}_{\mathrm{A}}^{\mathrm{x}}+2 \mathrm{M}_{\mathrm{B}}^{\prime}+4 \mathrm{O}_{\mathrm{O}}^{\mathrm{x}}+2 \mathrm{OH}_{\mathrm{O}}^{\circ}$. The solubility of the acceptor addition increases with the partial pressure of water, and the protons can be the dominant defects ensuring electroneutrality condition. However, practical use of the above reaction is difficult to implement, because the synthesis (annealing, sintering) would have to be carried at high temperatures, in which protons are only a small part of the existing defects [4].

Generally, there are two ways of proton transport described in the literature: vehicular mechanism and Grotthuss mechanism, shown schematically in Fig. 5. In the first one, the diffusion of protons takes place through movement of the carrier accompanied by the $\mathrm{H}^{+}$ion. Most often this is $\mathrm{OH}^{-}, \mathrm{H}_{3} \mathrm{O}^{+}$or $\mathrm{NH}_{4}^{+}$group [4]. Simulations and isotopic studies indicate that in perovskite oxides high temperature proton transport occurs within the structure according to the Grotthuss mechanism. In this case, $\mathrm{H}^{+}$ions move between successive oxygen anions, and not with $\mathrm{OH}^{-}$medium, as in vehicular mechanism [21]. It can be also stated that the mechanism of $\mathrm{H}^{+}$ions transport is similar in different families of oxides, due to the high degree of self-localization and a strong coupling between protons moving in the same crystal structure. This means that the hydrogen cations are located in the electron cloud of the oxygen anions, to form hydroxide ions having a positive charge $\mathrm{OH}_{0}{ }^{*}$ in respect to the (oxygen) lattice [4]. While proton interacts strongly in the created $\mathrm{O}-\mathrm{H}$ bond, it is affected by other, surrounding oxygen anions. Depending on the distance between two oxygens $(\mathrm{O}-\mathrm{O})$, protons can form the hydrogen bond between the two oxygen anions, which can be symmetrical (i.e. of the same length), if O-O distance is less than $0.24 \mathrm{~nm}$. However, if the distance is in the $0.25-0.28 \mathrm{~nm}$ range, proton is more strongly associated with one of the adjacent oxygens, and the binding sites are of different length [14]. The activation energy of the proton hopping 
from one oxygen to the next one depends on the O-O distance, due to a decrease of the electron density and increase of the potential between oxygens. Regardless of a class of oxide, it is approximately $2 / 3$ of the value of the activation energy of oxygen conduction (through vacancy mechanism). This observation can be explained by a fact that migration of protons is dependent on the oxygen network vibrations. Both, proton and oxygen conductivity require to overcome the same energy barrier, but while $\mathrm{O}^{2-}$ anion must overcome energy barrier of the migration process between the energy minima, the proton can jump when ion on which it is located overcomes $2 / 3$ of the energy barrier [4].

a)

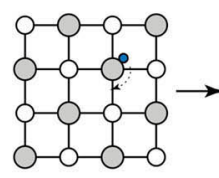

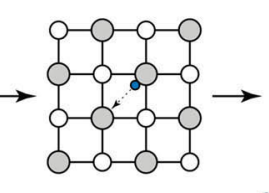

b)

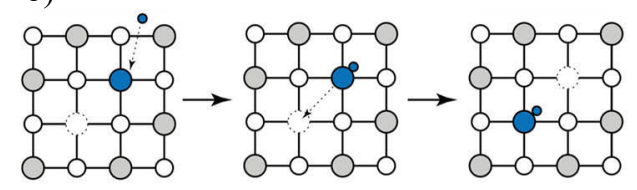

Fig. 5. Two types of proton transport mechanism: a) Grotthus type, b) vehicular type

Proton conductivity shows an important phenomenon called isotopic effect. This effect stems from a large difference in mass of $\mathrm{H}^{+}$and $\mathrm{D}^{+}$. Due to a higher mass, deuterium isotope moves slower through structure of the material (oxide) than hydrogen. There are two models describing such the effect: a classic model, which only takes into account change between frequency of vibration $\mathrm{O}-\mathrm{H}$ and $\mathrm{O}-\mathrm{D}$, and a pseudo-classic one that additionally takes into account quantum effects connected with the isotope change. From the first model, which says that mobility of protons $\mu$ in the HTPC is proportional to the frequency of hydrogen bond vibration, it can be stated that $\mu_{\mathrm{H}} / \mu_{\mathrm{D}} \approx \sqrt{ } 2$. Assuming that isotope change does not affect concentration of charge carriers, conductivity ratio can be given as $\sigma_{\mathrm{H}} / \sigma_{\mathrm{D}} \approx \sqrt{2}$. The pseudoclassic model allows to compute change of the energy of the basic state $\Delta E_{0}$ between proton and deuterium, which is $0.054 \mathrm{eV}$, and such difference of the activation energy of conductivity can be expected in the temperature range at which proton conductivity is dominant $[22,23]$.

\section{Overview of proton-conducting oxides}

In 1980s and 1990s Iwahara et al. discovered proton conductivity in $(\mathrm{Ba}, \mathrm{Sr}) \mathrm{CeO}_{3-\delta}$ oxides at high temperatures [24, 25], which triggered great interest and intensive research concerning HTPCs in many laboratories worldwide [26-29]. Initially, the B-site substituted $(\mathrm{Ba}, \mathrm{Sr})(\mathrm{Zr}, \mathrm{Ce}) \mathrm{O}_{3-\delta}$ perovskites were studied [30]. It was shown that choice of cations with different ionic radii has a profound effect on the degree of distortion from the cubic structure in these oxides. Considering preference of the cubic structure, B-site doped $\mathrm{BaIn}_{1-\mathrm{y}} \mathrm{M}_{\mathrm{y}} \mathrm{O}_{3-\delta}$ $\left(\mathrm{M}^{4+}=\mathrm{Zr}, \mathrm{Sn}\right)$ materials, having high content of In and a disordered oxygen vacancy sublattice, were also found to be of great interest [31,32]. Analysis of results of the available studies indicates that good proton conductivity is connected to high alkalinity of A cations and a high deviation from stoichiometry in the oxygen sublattice, but without oxygen vacancy ordering present $[4,33]$. Chemical composition of the oxide is strongly affecting mobility of protons inside the structure of perovskite-type oxide. The low value of the enthalpy of mobility of protons can be attributed to a presence of large cations in the A-sublattice, which allows for a better dynamics of movement of $\mathrm{H}^{+}$. The enthalpy of proton migration is also affected by the repulsion between $\mathrm{H}$ and $\mathrm{B}$ cations. In regular perovskites, where the $\mathrm{B}$ cation is on +5 oxidation state, the energy is much higher than for materials, in which the cations are at the +4 oxidation state [18]. Due to a small value of the energy migration and low defect formation energy, perovskite oxides can be generally considered as good proton conductors. 
Perovskites with a cubic structure (with Goldschmidt's tolerance fact $t \approx 1$ ), exhibit higher conductivity than materials exhibiting lower symmetry, because positions of oxygen ions are energetically equal, so there are no places in the structure that would require higher amount of energy, and $\mathrm{H}^{+}$jump is possible in any direction with equal probability [4]. In a group of perovskite-type HTPCs, one of the highest proton conductivity (on the order of $10^{-2} \mathrm{~S} \cdot \mathrm{cm}^{-1}$ at $600{ }^{\circ} \mathrm{C}$ show oxides based on the substituted $\mathrm{BaCeO}_{3}$. Unfortunately, these materials exhibit a significant decrease of the transfer of protons at elevated temperatures (proton transference number decreases) [34]. Although $\mathrm{SrCeO}_{3}$-based oxides have a lower conductivity of $\mathrm{H}^{+}$ions, their high temperature proton transference number remains high. However, problem associated with practical use of the abovementioned compounds is their chemical instability and relatively high reactivity in atmospheres containing $\mathrm{CO}_{2}$ or $\mathrm{SO}_{3}$ and water vapor [11]. The alternative candidates may be strontium or barium zirconates, having excellent chemical stability over a wide temperature range. However, they are characterized by a significantly lower conductivity (influence of grain boundaries), comparing to $\mathrm{BaCeO}_{3}$ [4]. Among high temperature proton conductors there are materials with more complex structure or a derivative from the perovskite one, such as for example $\mathrm{Sr}_{6-2 \mathrm{x}} \mathrm{Nb}_{2+2 \mathrm{x}} \mathrm{O}_{11+3 \mathrm{x}}$, $\mathrm{Sr}_{6-2 x} \mathrm{Ta}_{2+2 \mathrm{x}} \mathrm{O}_{11+3 \mathrm{x}}$ or $\left(\mathrm{Ba}_{1-\mathrm{y}} \mathrm{Ca}_{\mathrm{y}}\right)_{6} \mathrm{Nb}_{2} \mathrm{O}_{11}$. Those material can incorporate one molecule of water per one molecule of compound, and show pure protonic conductivity $\left(10^{-3} \mathrm{~S} \cdot \mathrm{cm}^{-1}\right)$ at $600{ }^{\circ} \mathrm{C}[35]$. Other type of the structure that shows proton conductivity is brownmillerite one, observed for $\mathrm{Ba}_{2}\left(\mathrm{In}_{1-\mathrm{x}} \mathrm{Ti}_{\mathrm{x}}\right)_{2} \mathrm{O}_{5+\delta}$ materials, which show $\mathrm{H}^{+}$conductivity of $10^{-3} \mathrm{~S} \mathrm{~cm}^{-1}$ at 450 ${ }^{\circ} \mathrm{C}$ [36]. Recently, also $\mathrm{La}_{6} \mathrm{WO}_{12}, \mathrm{La}_{2} \mathrm{Zr}_{2} \mathrm{O}_{7}$ or $\mathrm{LaNbO}_{4}$ materials are of interest, which stems from a lack of $\mathrm{Ba}$ in their structure $[37,38]$.

\section{Structure and transport in $\mathrm{Ba} 0.9 \mathrm{La} 0.1 \mathrm{Zr} 0.25 \mathrm{Sn}_{0.25} \mathrm{In}_{0.5} \mathrm{O}_{2.8}$}

Choice of the chemical composition of perovskite-type HTPC has profound influence on the physicochemical properties of the material. While acceptor-type chemical substitution on the B-site is commonly used to modify properties (mainly, increase concentration of the intrinsic oxygen vacancies), introduction of +3 cations $\left(\mathrm{Ln}^{3+}\right)$ at the A-site is relatively less studied, as it would act in opposite way, concerning concentration of $\mathrm{V}_{\mathrm{O}}{ }^{*}$. However, for a small degree of substitution, such doping may be of interest, especially concerning studies of relationship between crystal structure and transport properties of the materials.

For the particular example of $\mathrm{Ba}_{0.9} \mathrm{La}_{0.1} \mathrm{Zr}_{0.25} \mathrm{Sn}_{0.25} \mathrm{In}_{0.5} \mathrm{O}_{2.8}$ composition, which was obtained by a solid state reaction at $1600{ }^{\circ} \mathrm{C}$, crystal structure was determined as cubic, with $P m-3 m$ symmetry, and unit cell parameter $\mathrm{a}=4,1676(1) \AA$. The recorded in different atmospheres (synthetic dry air, wet air with ca. 3 vol. $\% \mathrm{H}_{2} \mathrm{O}$ or $\mathrm{D}_{2} \mathrm{O}$ ) impedance data for a dense sinter, presented in Nyquist-type plots, are shown in Fig. 6. As can be seen in Fig. $6 \mathrm{a}$, at $400{ }^{\circ} \mathrm{C}$ the impedance curve comprises of three semi-circles, first of which (at the highest frequency) can be attributed to the bulk ionic conductivity, second one to the grain boundaries, and the one visible at lowest frequencies to the influence of the electrode. A visible decrease of size of first two, when the atmosphere was switched from dry air to the $\mathrm{D}_{2} \mathrm{O}$ - and $\mathrm{H}_{2} \mathrm{O}$-containig one proves an existence of proton (or $\mathrm{D}^{+}$) component of the conductivity $[39,40]$. At the same time, impedance data registered at $600{ }^{\circ} \mathrm{C}$ suggests an appearance of electronic component of the conductivity, as the recorded spectra are shifted in relation to the origin. Summary of the transport data in $\mathrm{Ba}_{0.9} \mathrm{La}_{0.1} \mathrm{Zr}_{0.25} \mathrm{Sn}_{0.25} \mathrm{In}_{0.5} \mathrm{O}_{2.8}$ is presented in Tab. 1. While the protonic (or deuterium-related) conductivity is relatively high at $550{ }^{\circ} \mathrm{C}$, the respective transference numbers are low in the considered oxide. This indicates that in temperatures below $600{ }^{\circ} \mathrm{C}$ the oxygen vacancy-related conductivity is considerable. The mentioned appearance of the electronic component of the conductivity at $600{ }^{\circ} \mathrm{C}$ and above, while detrimental for the electrolyte behavior, may be utilized considering application of this material for construction of the electrodes in PCFCs (e.g. Fig. 3c). 
a)

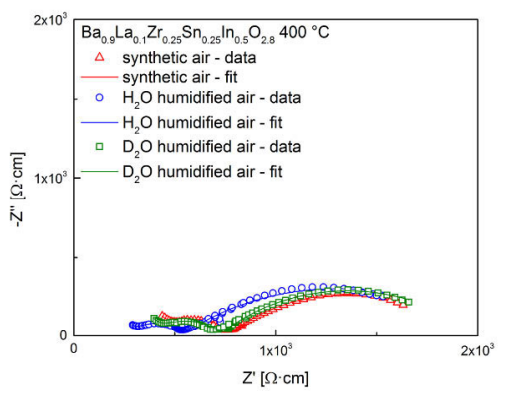

b)

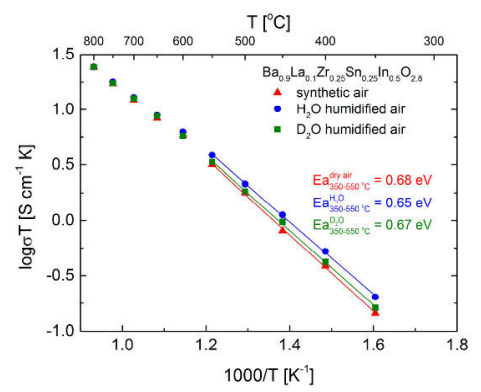

Fig. 6. a) Nyquist-type plot of impedance data recorded at $400{ }^{\circ} \mathrm{C}$, b) temperature dependence of electrical conductivity for $\mathrm{Ba} 0 .{ }_{0} \mathrm{La}_{0.1} \mathrm{Zr}_{0.25} \mathrm{Sn}_{0.25} \mathrm{In}_{0.5} \mathrm{O}_{2.8}$ in different atmospheres.

Table 1. Transport properties of $\mathrm{Ba} 0.9 \mathrm{La} 0.1 \mathrm{Zr}_{0.25} \mathrm{Sn}_{0.25} \mathrm{In}_{0.5} \mathrm{O}_{2.8}$ at different temperatures.

\begin{tabular}{|l|c|c|}
\hline property & $\mathbf{T}=\mathbf{3 5 0}^{\circ} \mathbf{C}$ & $\mathbf{T}=\mathbf{5 5 0}^{\circ} \mathbf{C}$ \\
\hline Protonic conductivity $\sigma_{\mathrm{H}}\left(\sigma_{\mathrm{H} 2 \mathrm{O}}-\sigma_{\mathrm{dry}}\right)\left[\mathrm{S} \cdot \mathrm{cm}^{-1}\right]$ & $0.9 \cdot 10^{-4}$ & $0.8 \cdot 10^{-3}$ \\
\hline Deuterium conductivity $\sigma_{\mathrm{D}}\left(\sigma_{\mathrm{D} 2 \mathrm{O}}-\sigma_{\mathrm{dry}}\right)\left[\mathrm{S} \cdot \mathrm{cm}^{-1}\right]$ & $0.3 \cdot 10^{-4}$ & $0.2 \cdot 10^{-3}$ \\
\hline Protonic transference number $\mathrm{t}_{\mathrm{H}}\left(\sigma_{\mathrm{H}} / \sigma_{\mathrm{H} 2 \mathrm{O}}\right)$ & 0.29 & 0.18 \\
\hline Deuterium transference number $\mathrm{t}_{\mathrm{D}}\left(\sigma_{\mathrm{D}} / \sigma_{\mathrm{D} 2 \mathrm{O}}\right)$ & 0.11 & 0.05 \\
\hline
\end{tabular}

\section{Concept of Symmetrical Fuel Cell}

A novel idea of a symmetrical cell, built using a redox-stable electrode material as both, the anode and cathode, was shown recently [41]. In the classic cell, anode and cathode are made of different materials, which is directly connected with very strict requirements (e.g. chemical stability and sufficient transport properties under reducing and oxidizing atmospheres). In the symmetrical construction, both electrodes are made of the same oxide material or composite (Fig. 7a). Initially, this approach was utilized alleviate problems with possible sulfur poisoning or coke formation on the surface of the SOFC anode operating with hydrocarbon-type fuels, e.g. methane, but also synthesis gas. It was shown that anodes made of Mo- and W-containing materials (e.g. $\mathrm{Ba}_{2-\mathrm{x}} \mathrm{Sr}_{\mathrm{x}} \mathrm{M}_{2-\mathrm{x}} \mathrm{Mo}_{\mathrm{x}} \mathrm{O}_{6-\delta}$ and $\mathrm{Ba}_{2-\mathrm{x}} \mathrm{Sr}_{\mathrm{x}} \mathrm{M}_{2-\mathrm{x}} \mathrm{W}_{\mathrm{x}} \mathrm{O}_{6-\delta}$, M: $\mathrm{Mg}, \mathrm{Fe}, \mathrm{Co}, \mathrm{Ni}$, etc.) are more tolerant to carbon deposition than Ni-based cermets [41, 42]. Interestingly, these compounds are also tolerant to a changing oxygen partial pressure, which allows for example to flush the anode with air, in order to remove any sulfur or carbon species adsorbed on the electrode, and thereby to regenerate the electrode after sulfur or coke deactivation. As some of the mentioned oxides are also usable in air at elevated temperatures and show suitable electrical conductivity, they can be successfully applied on the cathode side. This new configuration with identical materials (or composites) used on both electrodes leads to a number of advantages. One is related to a fact that manufacturing process of such SOFCs can be more simple and cheaper (only one sintering process is needed to prepare both electrodes). In addition, a redox stable cathode is also expected to enhance the cathode durability, since oxygen partial pressure at the cathode triple phase boundary region can be quite low, especially when SOFCs are operated at a low cell voltage.

Fig. 7b shows results of an exemplary cell (obtained by authors) built with ca. $0.5 \mathrm{~mm}$ think $\mathrm{Ce}_{0.8} \mathrm{Gd}_{0.2} \mathrm{O}_{1.9}$ oxygen ions-conducting electrolyte, and composite electrodes (anode and cathode) consisting of cation-disordered $\mathrm{SrFe}_{0.75} \mathrm{Mo}_{0.25} \mathrm{O}_{3-\delta}$ oxide mixed in 3:2 wt. ratio with electrolyte powder. The obtained power density was about $80 \mathrm{~mW} \cdot \mathrm{cm}^{-2}$ at $900{ }^{\circ} \mathrm{C}$ when fueled with hydrogen. In the case of methane or propanol fuels used, the registered power density is such symmetrical configuration did not exceed $10 \mathrm{~mW} \cdot \mathrm{cm}^{-2}$, but resistance of the used material to carbon deposition and improved properties concerning sulfur poisoning are a basis for further studies. Recently, a significant number of emerging literature reports on the subject can be noticed [43-45]. 
a)

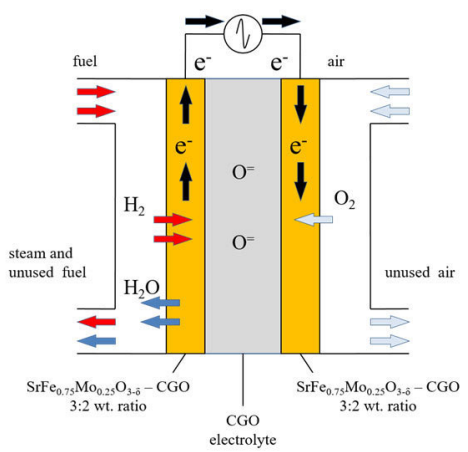

b)

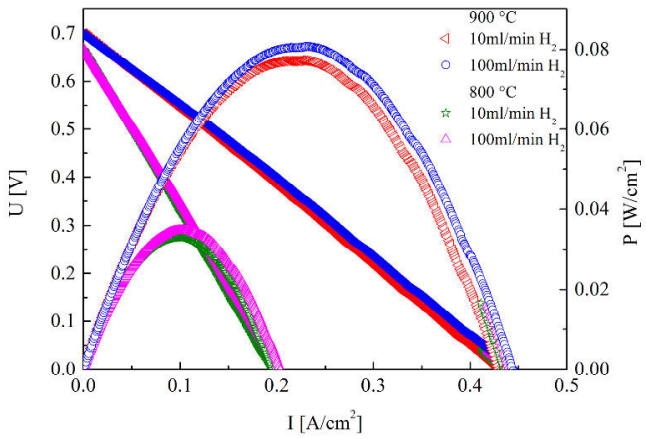

Fig. 7. a) Concept of symmetrical SOFC construction, based on [41] with exemplary electrolyte and electrode materials shown, b) performance data measured for symmetrical cell (see text for details).

Symmetrical cell construction in the case of SOFCs with oxygen-conducting electrolyte seems justified. Similar approach can be also considered in the case of PCFCs and SOECs with proton-conducting electrolyte. Initial results concerning the abovementioned group obtained by the authors indicate that a relatively high resistance of the electrode/electrolyte is among the most important issues, which need to be solved. Also, it seems that interfusion of cations between such electrode materials and commonly used proton-conducting electrolytes at the temperatures needed for manufacturing of the cells will be a hindrance. More studies are needed in order to design effectively working electrode material for such cells, but symmetrical cell approach also seems to be justified for PCFCs and SOECs.

\section{Summary}

Proton-conducting oxides seem as an interesting choice for the solid electrolyte for high temperature fuel cells. However, there are still material-related issues, which needs to be solved before efficient PCFCs can be built. This includes development of functional electrolytes, but also electrode materials exhibiting high proton conductivity. It seems that it is achievable by a proper selection of composition of the compounds and composites.

Acknowledgements The project was funded by the National Science Centre Poland (NCN) on the basis of the decision number DEC-2012/05/E/ST5/03772.

\section{References}

1. A. Gugliuzza, A. Basile, Membranes For Clean And Renewable Power Applications, Woodhead Publishing Limited (2014)

2. V.V. Kharton, Solid State Electrochemistry II: Electrodes, Interfaces And Ceramic Membranes, Wiley-Vch Verlag \& Co. Kgaa (2011)

3. N. Ito, M. Iijima, K. Kimura, S. Iguchi, J. Power Sources, 152 (2005) 200

4. T. Ishihara, Perovskite Oxide for Solid Oxide Fuel Cells, Springer (2009) NY,

5. J. W. Fergus, R. Hui, X. Li, D. P. Wilkinson, J. Zhang: Solid Oxide Fuel Cells Materials Properties and Performance, CRC Press (2009) Boca Raton,

6. S.C. Singhal, K. Kendall: High Temperature Solid Oxide Fuel Cells: Fundamentals, Design and Applications, Elsevier Science (2003) Oxford

7. Development of SOFC for Products, Mitsubishi Heavy Industries, Ltd.

8. M.L. Toebes, J.H. Bitter, A.J. van Dillen, K.P. de Jong, Catal. Today, 76 (2002) 33

9. Fuel Cell Today, 13 Nov. 2016, http://www.fuelcelltoday.com/applications/stacionary

10. A.L. Dickcs, J. Power Sources, 61 (1996) 113 
11. R.H. Cunningham, C.M. Finnerty, R.M. Ormerod: Solid Oxide Fuel Cells V. The Electrochemical Society Proceedings, Pennington (1997) NJ

12. S.H. Jensen, X. Sun, S.D. Ebbesen, R. Knibbe, M. Mogensen, Int. J. Hydrogen Energy, 35 (2010) 9544

13. W. Zając, D. Rusinek, K. Zheng, J. Molenda, Cent. Eur. J. Chem., 11 (2013) 471

14. A. Mielewczyk-Gryń, Właściwości strukturalne i transportowe ceramicznego przewodnika protonowego - domieszkowanego niobanu lantanu, Dissertation for the degree of Philosophiae Doctor

15. L. Yang, Z. Liu, S. Wang, Y.M. Choi, C. Zuo, M. Liu, J. Power Sources, 195 (2010) 471

16. T. Kariya, H. Tanaka, T. Hirono, T. Kuse, K. Yanagimoto, K. Uchiyama, M. Henmi, M. Hirose, I. Kimura, K. Suu, H. Funakubo, J. Alloys Compd., 654 (2016) 171

17. K.D. Kreuer, Solid State Ionics, 136 (2000) 149

18. Y. Wang, A. Chesnaud, E. Bevillon, J. Yang, G. Dezanneau, Int. J. Hydrogen Energy, 36 (2011) 7688

19. E. Fabbri, D. Pergolesi, E. Traversa, Chem. Soc. Rev., 39 (2010) 4355

20. K.D. Kreuer, Annu. Rev. Mater. Res., 33 (2003) 333

21. N. Agmon, Chem. Phys. Lett. 244 (1995) 456

22. N. Bonanos, A. Huijser, F.W. Poulsen, Solid State Ionics 275 (2015) 9

23. N. Bonanos, Solid State Ionics, 145 (2001) 265

24. H. Iwahara, T. Esaka, H. Uchida, N. Maeda, Solid State Ionics 3/4 (1981) 359

25. H. Iwahara, H. Uchida, K. Ono, K. Ogaki, J. Electrochem. Soc. 135 (1988) 529

26. T. Norby, Solid State Ionics, 40/41 (1990) 857-862.

27. E. Matsushita, T. Sasaki, Solid State Ionics 125 (1999) 31-37.

28. W. Zając, E. Hanc, A. Gorzkowska-Sobas, K. Świerczek, J. Molenda, Solid State Ionics 225 (2012) 297-303.

29. W. Zając, E. Hanc, Funct. Mater. Lett. 7 (2014) 1440014

30. P. Berastegui, S. Hull, F. J. García-García, S.-G. Eriksson, J. Solid State Chem. 164 (2002) 119-130.

31. P. Colomban, Ann. Chim. Sci. Mat, 24 (1999) 1-18.

32. J. Jankovic, D.P. Wilkinson, R. Hui, J. Power Sources 201 (2012) 49-58.

33. K. Świerczek, W. Zając, A. Klimkowicz, K. Zheng, N. Malikova, B. Dabrowski, Solid State Ionics, 275 (2015) 58

34. H. Iwahara, T. Yajima, T. Hibino, H. Ushida, J. Electrochem. Soc., 140 (1993) 1687

35. S.M. Haile, D.L. West, J. Campbell, J. Mater. Res., 13 (1998) 1576

36. K.-D. Kreuer, A. Fuchs, J. Maier, Solid State Ionics, 77 (1995) 157

37. R. Haugsrud, Solid State Ionics, 178 (2007) 555

38. T. Omata, K. Ikeda, R. Tokashiki, S. Otsuka-Yao-Matsuo, Solid State Ionics, 167 (2004) 389

39. A.S. Nowick, A.V. Vaysleyb, Solid State Ionics 97 (1997) 17-26

40. Y. Aoki, S. Kobayashi, T. Yamaguchi, E. Tsuji, H. Habazaki, K. Yashiro, T. Kawada,

T. Ohtsuka, J. Phys. Chem., 2016 (29) 15976

41. Q. Li, V. Thangadurai, J. Power Sources, 196 (2011) 169

42. S. Vasala, M. Lehtimäki, S.C. Haw, J.M. Chen, R.S. Liu, H. Yamauchi, M. Karppinen, Solid State Ionics, 181 (2010) 754

43. D.M. Bastidas, S. Tao, J.T.S. Irvine, J. Mater. Chem., 17 (2006) 1603

44. X. Zhu, Z. Lü, B. Wei, X. Huang, Y. Zhang, W. Su, J. Power Sources, 196(2) (2011) 729

45. T.L. Cable, S.W. Sofie, J. Power Sources, 174(1) (2007) 221 